\title{
Políticas de qualificação profissional no Leste Metropolitano Fluminense
}

Professional qualification policies in the Eastern Metropolitan of Rio de Janeiro Les politiques de qualification professionnelle de l'Est Métropolitain à Rio de Janeiro

\section{Taís de Santana Ferreira}

\section{(2) OpenEdition}

\section{Journals}

\section{Edição electrónica}

URL: http://journals.openedition.org/espacoeconomia/312

DOI: $10.4000 /$ espacoeconomia.312

ISSN: 2317-7837

\section{Editora}

Núcleo de Pesquisa Espaço \& Economia

\section{Refêrencia eletrónica}

Taís de Santana Ferreira, « Políticas de qualificação profissional no Leste Metropolitano Fluminense », Espaço e Economia [Online], 2 | 2013, posto online no dia 09 março 2013, consultado o 01 maio 2019. URL : http://journals.openedition.org/espacoeconomia/312 ; DOI : 10.4000/espacoeconomia.312

Este documento foi criado de forma automática no dia 1 Maio 2019

(c) NUPEE 


\title{
Políticas de qualificação profissional no Leste Metropolitano Fluminense
}

\author{
Professional qualification policies in the Eastern Metropolitan of Rio de Janeiro \\ Les politiques de qualification professionnelle de l'Est Métropolitain à Rio de \\ Janeiro
}

Taís de Santana Ferreira

\section{Introdução}

1 A formação profissional é uma modalidade de ensino ligada diretamente ao trabalho. Os diferentes tipos de formação de mão-de-obra se estabelecem a partir da ação e da implantação de instituições de formação profissional. Estas possuem uma lógica espacial geralmente relacionada com a territorialização de investimentos produtivos, que exigem maior qualificação do trabalho. Nesta perspectiva, este artigo objetiva analisar a política de qualificação profissional no Leste metropolitano fluminense, área diretamente impactada pela implantação do Complexo Petroquímico do Rio de Janeiro (Comperj).

o Comperj é um projeto da empresa Petrobras que, a princípio, será composto por um complexo que compreende uma refinaria e indústrias de segunda geração, mas que já nasce com a pretensão de atrair indústrias de terceira geração para o seu entorno. Este projeto chama atenção não só por sua localização na periferia da metrópole, mas também por suas dimensões espaciais, e, neste sentido, pelos seus possíveis impactos ambientais e sociais.

o Comperj também inclui a implantação de uma política de qualificação profissional nos municípios de sua área de abrangência. Desta forma, com o intuito de compreender como se configurou essa política e apontar algumas de suas repercussões, foram realizadas entrevistas com coordenadores e diretores de instituições de formação profissional da região, incluindo a análise dos planos e projetos de qualificação. 


\section{O processo de reestruturação do Leste Metropolitano Fluminense}

4 No município de Itaboraí, na periferia da Região Metropolitana do Rio de Janeiro, está sendo construído o Comperj, que ocupará uma área de 45 milhões de metros quadrados, se configurando o maior investimento individual de toda a história da Petrobras, orçado em 8,4 bilhões de dólares. Sua relevância também reside no dado de que no Brasil não se produz quantidades suficientes de gás natural e nafta para o setor petroquímico nacional. Além disso, o complexo também será capaz de refinar o petróleo pesado extraído da Bacia de Campos, pouco valorizado no mercado internacional.

5 Segundo o Instituto Brasileiro de Petróleo, Gás e Biocombustíveis (IBP, 2009) a Bacia de Campos é a bacia petrolífera que mais produz na margem continental brasileira, respondendo atualmente por mais de $80 \%$ da produção nacional de petróleo. Essa bacia estende-se por 100 mil quilômetros quadrados, abrangendo a área desde o Estado do Espírito Santo, nas imediações da cidade de Vitória, até Arraial do Cabo, na Região dos Lagos fluminense. Espera-se que, com a instalação do Comperj, a produção de petróleo nesta região possa gerar para o país uma economia de divisas de dois bilhões de dólares anuais.

6 A implantação do Comperj tem relação com o contemporâneo processo de reestruturação espacial do território do estado do Rio de Janeiro, dando novos contornos ao espaço metropolitano. Objetiva retomar o crescimento econômico do estado e promover uma maior inserção na economia global, ancorado em investimentos logísticos e produtivos realizados pelo estado ou nos recursos de empresas públicas e privadas na esfera produtiva dentro e fora da metrópole (OLIVEIRA, 2008).

7 Com o anúncio da localização do Comperj constituiu-se o Consórcio Intermunicipal da Região Leste Fluminense (Conleste) em 2006. Foi uma iniciativa de onze municípios da área de abrangência do empreendimento, com a proposta de promover o desenvolvimento local equilibrado através de planejamento e execução de ações coordenadas. O Leste Fluminense era composto no ano de 2006 pelos municípios metropolitanos de Itaboraí, São Gonçalo, Niterói, Maricá, Guapimirim, Tanguá e Magé, e pelos municípios da Região das Baixadas Litorâneas, a saber: Cachoeiras de Macacú, Silva Jardim, Casimiro de Abreu e Rio Bonito. No ano de 2010 os municípios de Araruama e Teresópolis se integraram ao consórcio; o primeiro parte das Baixadas Litorâneas e o segundo da região Serrana.

Nos municípios dessa região (Leste Fluminense) foram implantados os Centros de Integração do Comperj, que correspondem a unidades de oferecimento de cursos resultantes da parceria com instituições de ensino e as prefeituras envolvidas. Em rápida entrevista, um professor do SENAI asseverou que tais oferecem a oportunidade para a pessoa se tornar competitiva no mercado, mas evidentemente não são garantia de emprego.

9 A iniciativa de criação destes Centros de Integração faz parte do Programa de Mobilização da Indústria Nacional de Petróleo e Gás Natural (PROMINP). O objetivo é capacitar cerca de 30 mil profissionais da região, em 60 tipos de cursos gratuitos. O RIMA prevê que a falta de qualificação por parte da população da região poderá gerar uma migração de 
mão-de-obra de outros lugares para o local de desenvolvimento e implementação do Comperj, atraída pelas oportunidades de trabalho geradas.

Neste panorama, também é projetada a formação de um eixo industrial associado à produção petrolífera, com a integração econômica e industrial dos municípios do entorno do Comperj, no Leste Fluminense, aos municípios que compõem a região diretamente impactada pelas atividades extrativistas -- denominada Região produtora de Petróleo e Gás. Esta é composta por municípios do Norte Fluminense (Carapebus, Campos dos Goytacazes, Conceição de Macabu, Macaé, Quissamã, São Francisco de Itabapoana e São João da Barra) e das Baixadas Litorâneas (Casimiro de Abreu e Rio das Ostras).

11 Evidencia-se dessa forma uma maior integração do território por força da formação ou consolidação de áreas industriais no estado do Rio de Janeiro. Expande-se a influência do espaço metropolitano para além dos seus limites tradicionais, incorporando a este espaço cidades e aglomerados urbanos mais afastados (OLIVEIRA, 2007).

12 A implantação do Comperj é, em grande parte, uma expressão do processo de reestruturação produtiva, que alterou as formas de organização do trabalho e das empresas. Esta reorganização do trabalho resultou em desemprego, devido tanto ao processo de descentralização quanto à inserção de novas técnicas no processo de produção, aumentando a exploração do trabalho e reduzindo a quantidade de mão-deobra necessária.

13 Esse processo de reestruturação teve consequências na estruturação das instituições de formação profissional na região. Um exemplo significativo é do SENAI (unidade de Niterói), localizado no bairro Barreto, que foi criado em 1949 para o atendimento da indústria naval da região. No fim da década de 80 e início de 90 , o setor naval sofreu um declínio, reduzindo a sua demanda por mão-de-obra. Isto resultou na reestruturação e criação de novos cursos pelo SENAI, diversificando sua área de atuação. Hoje possui cursos universais no mercado de trabalho, como os das áreas de Tecnologia da Informação, Gestão e Segurança. Porém, com o reaquecimento do setor naval a escola está se reestruturando novamente, com os cursos de soldagem e caldeiraria. Também foram implementados os cursos técnicos em Petróleo e Gás em 2005 e Segurança do Trabalho em 2002.

Edward Soja aponta o momento contemporâneo como sendo a mais recente tentativa de se reestruturar as matrizes espaciais e temporais do capitalismo. Sua análise tem como ponto de partida a ligação afirmativa entre a espacialização e a reestruturação. Para o autor,

a reestruturação deve ser considerada originária de e reativa a graves choques nas situações práticas sociais preexistentes, e desencadeadora de uma intensificação de lutas competitivas pelo controle das forças que configuram a vida material [...]. Como tal, a reestruturação se enquadra entre a reforma parcial e a transformação revolucionária, entre a situação de perfeita normalidade e algo completamente diferente (SOJA, 1993, p. 194).

Neste sentido, o processo de reestruturação produtiva pode ser interpretado como uma resposta à crise estrutural do capitalismo iniciada nos anos 1960. O capital consegue imensos ganhos de produtividade com menos mão-de-obra, colocando em xeque a associação direta entre crescimento econômico e a geração de empregos. Mas o capital não pode eliminar o trabalho vivo do processo de criação de valores (ANTUNES, 2003); ele deve aumentar a utilização e a produtividade do trabalho de modo a intensificar as formas de extração do sobretrabalho em tempo cada vez mais reduzido. 0 capital recorre 
cada vez mais às formas precarizadas e intensificadas de exploração do trabalho, que se torna ainda mais fundamental para realização de seu ciclo reprodutivo num mundo onde a competitividade é a garantia de sobrevivência da empresa capitalista (ANTUNES, 2009).

Com o advento de modelos flexíveis de produção, o trabalhador fordista foi definido como "desqualificado" devido à alta divisão técnica do trabalho. No sistema flexível o trabalhador deve se tornar qualificado e polivalente, e por este motivo torna-se tão relevante a qualificação profissional. As mudanças técnicas e organizacionais do trabalham exigem um novo tipo de trabalhador. Diante de um quadro de desemprego e da lógica da competitividade, as empresas procuram explorar ao máximo o seu conhecimento profissional.

Se Marx dizia nos Manuscritos Econômicos e Filosóficos que o trabalhador torna-se mercadoria juntamente com seu trabalho ao produzir bens para reprodução do capital, agora, na economia pós-industrial, até mesmo produção intelectual do trabalhador, sua subjetividade, é passível de troca, de comercialização. Esta se torna não só um fator determinante na hora da contratação do empregado (preferência pela mão-de-obra qualificada), mas também uma mercadoria, um objeto de compra e venda (RAMOS, 2008).

17 A Petrobras realizou a reforma da Escola Técnica Estadual Henrique Lage (ETEHL) no município de Niterói, no sentido de adequar a instituição às atuais transformações do mercado e processos de trabalho. Os cursos técnicos mais antigos dessa escola são os cursos de estrutura navais, de máquinas navais e de eletrônica, que começaram a funcionar 1969, e os cursos de eletrotécnica e de edificações, iniciados em 1976. O objetivo da reforma foi oferecer cursos na área de atuação do Comperj, e assim foram planejados cursos de qualificação de um ano voltados para quem já possui curso técnico em edificações (topografia e estruturas metálicas), construção naval e máquinas navais (solda, pintura e isolamento, montagem e mecânica), eletrônica e eletrotécnica (instrumentista de sistemas, instrumentista montador e elétrica).

\section{Políticas de qualificação profissional}

18 Um dos principais desdobramentos das políticas de emprego no Brasil nas últimas décadas foi a implantação de políticas de qualificação profissional. Ramos discute as teorias oriundas de duas diferentes abordagens sobre o desemprego: o modelo clássico e o keynesiano. 0 primeiro associa a responsabilidade do desemprego ao mercado de trabalho, por ser concorrencial e seletivo, e justamente é este mercado de trabalho que geralmente compõe a base das políticas de formação profissional. 0 segundo indica que este problema está relacionado com a falta de crescimento econômico, na concepção tornada predominante na época de domínio do fordismo.

Nesse sentido, as Políticas de Emprego supõem, implicitamente, que os problemas do desemprego estão gerados no mercado de trabalho. [...] Supor que o principal determinante na solução do problema da falta de oportunidades de emprego é o crescimento, como supunha Keynes, implica em relegar a um lugar secundário, só coadjuvante, às políticas de emprego. [...] Em outros termos, uma leitura menos radical poderia afirmar que, em cada momento do tempo, existe uma restrição que é a relevante. [...] Nessa linha, se o diagnóstico é que a principal fonte do desemprego é a falta de "empregabilidade" dos desocupados, isso implica em supor que a taxa de crescimento é suficiente e, mais ainda, que a mesma dificilmente será elevada, dado que esforços por acelerar o desenvolvimento vão esbarrar na falta de mão-de-obra. Contudo, não se pode admitir, por uma questão de consistência teórica, que 
ambos os problemas sejam simultâneos. Assim, se a restrição relevante é o crescimento, as Políticas de Emprego são irrelevantes em termos práticos. Contrariamente, se existem vagas mas os desocupados não conseguem preenchê-las, serão vãos os esforços para elevar o número de vagas oferecidas, visto que o resultado será a mesma quantidade de desocupados e um número superior de postos de trabalho criados e não ocupados (RAMOS, 2003, p. 26, grifos meus).

19 A qualificação profissional apresenta-se no Plano Nacional de Qualificação Profissional (2003-2007) como "fator de inclusão social, de desenvolvimento econômico, com geração de trabalho e distribuição de renda"; além disso, "quanto mais associada estiver a uma visão educativa que a tome como um direito de cidadania, mais poderá contribuir para a democratização das relações de trabalho e para imprimir um caráter social e participativo ao modelo de desenvolvimento". Estas são as bases de política pública de qualificação, onde a educação é vista como o grande motor do desenvolvimento social, depositando imensas expectativas e responsabilidades neste setor. Esta concepção com base no caráter social da qualificação profissional deposita imensas expectativas e responsabilidades no setor, no momento em que

O nexo entre trabalho, educação e desenvolvimento, no âmbito das Políticas Públicas de Qualificação, pressupõe a promoção de atividades político-pedagógicas baseadas em metodologias inovadoras dentro de um pensamento emancipatório de inclusão, tendo o trabalho como principio educativo; o direito ao trabalho como um valor estruturante da cidadania; a qualificação como uma política de inclusão social e um suporte indispensável do desenvolvimento sustentável; a associação entre a participação social e a pesquisa como elementos articulados na construção desta política e na melhoria da base de informação sobre a relação trabalho-educaçãodesenvolvimento. Possibilita com tudo isso a melhoria das condições de trabalho e da qualidade social de vida da população (PNQ, 2003, pp. 25-26, grifos meus).

20 Este texto possui um caráter próximo ao publicitário, explícito no uso de palavras chaves como "desenvolvimento sustentável", “inclusão social", "caráter emancipatório", "principio educativo", “direito ao trabalho", "cidadania", “qualidade social” etc. Elegemse tais conceitos como meta da educação profissional sem uma definição clara dos mesmos. Aparecem assim colocados devido à conotação positiva que possuem, procurando reforçar a legitimidade de tal política.

21 A implantação do IFRJ - Instituto Federal de Educação, Ciência e Tecnologia do Rio de Janeiro (antigo Cefet de Química - CEFETEQ) em São Gonçalo foi resultado do projeto do governo federal de expansão do ensino técnico em um processo de interiorização do ensino técnico. O IFRJ se organiza a partir das demandas do mercado local, e assim esta unidade de oferece desde 2008 o curso técnico em segurança no trabalho.

Segundo o Ministério da Educação - MEC (2010), o setor educação profissional é o que mais cresce no país em número de matrículas, tanto nas esferas particular quanto pública. Isto indica uma expansão quantitativa do setor no Brasil.

Estas políticas públicas, ora são vistas como oportunas e eficazes por potencializarem a melhoria das condições de vida e de trabalho ao trabalhador, ampliando os seus direitos de cidadania, ora criticadas, "no sentido de que a sua efetividade não possui correspondência com os recursos investidos" (SCHMIDT, 2001, p. 9), ou por não oferecerem alternativas para o trabalho e nem efetivo acesso aos direitos de cidadania para os segmentos em situação de risco. Ainda sim, são elas quem ganham, no quadro da precarização do trabalho, das exigências internacionais e sindicais por mais educação e mais qualificação das populações nacionais, novas dimensões e assumem novos conteúdos 
sociais e políticos, impulsionando os governos brasileiros a reverem suas políticas de educação e de qualificação do trabalhador (PRESTES, 2009, p. 53).

Colocando em relevo a dimensão social do pretensioso projeto da Petrobras emerge a pergunta: de que forma pretende-se promover esse desenvolvimento social? Segundo o Relatório de Impacto Ambiental (RIMA) do Comperj a resposta é a geração de empregos. O empreendimento promete gerar mais de 200 mil empregos diretos, indiretos e por "efeito-renda", em nível regional e nacional, durante os cinco anos da obra e após a entrada em operação.

Considerando as atuais transformações do mercado de trabalho que resultaram, de maneira geral, na precarização e no desemprego, o discurso que se torna hegemônico no Brasil é a afirmação de que existem empregos, mas não há mão-de-obra qualificada. De acordo com o RIMA os municípios da região diretamente impactada são caracterizados por baixo nível de escolaridade, e para resolver este problema estruturou-se uma política de qualificação profissional para essa região, promovida pela Programa Nacional de Mobilização da Indústria de Petróleo e Gás Natural (Prominp) e seguindo os mesmos pressupostos do Plano Nacional de Qualificação (PNQ).

Ferretti (FERRETTI, 1993) discute a controversa definição da qualificação profissional e qual o seu papel na sociedade. $O$ autor faz uma crítica ao discurso que tende a descarregar na área educacional uma responsabilidade que não lhe cabe, como o desenvolvimento econômico e a modernização da produção no país, e demonstra preocupação com o tipo de educação que devemos defender, pois desconsiderando a complexidade do problema corre-se o risco de acabar defendendo o atrelamento direto da educação ao setor produtivo. Quando analisamos a orientação da política de qualificação profissional, logo observamos que atrelar a educação diretamente ao setor produtivo é conformar uma educação utilitarista voltada para o atendimento das demandas do mercado.

A Escola Técnica Industrial, localizada em São Gonçalo, oferece cursos para as áreas de petróleo e gás. Autodenominada a maior indústria-escola do Brasil, anuncia em seu site que o salário inicial de solda e caldeiraria é em torno de $\mathrm{R} \$ 1.700,00$ (mil e setecentos reais), evidenciando a dimensão utilitarista de sua formação e reforçando indiretamente a ideia de falta de mão-de-obra qualificada.

O discurso do Comperj pressupõe que o problema eminente da região é o desemprego, que tem como causa principal o baixo índice de escolaridade da população, e que assim o problema reside no mercado de trabalho. Em controponto, este empreendimento pretende promover um crescimento econômico, que irá gerar empregos na região, evidenciando-se a inconsistência teórica apresentada por Ramos (RAMOS, 2003). A situação é ainda um pouco mais complexa; com base na análise de Segnini (SEGNINI, 2000), houve um crescente desemprego de trabalhadores escolarizados, sobretudo nos setores mais modernos da sociedade, mostrando que no atual momento de reestruturação produtiva o desemprego já seja resultado da ausência de crescimento econômico, mas algo inerente ao mesmo.

Neste contexto, as estratégias o capital para retomar sua acumulação ampliada resultaram no que Harvey denomina de acumulação flexível, apoiada

na flexibilidade dos processos de trabalho, dos mercados de trabalho, dos produtos e padrões de consumo. Caracteriza-se pelo surgimento de setores de produção inteiramente novos, novas maneiras de fornecimento de serviços financeiros, novos mercados e, sobretudo, taxas altamente intensificadas de inovação comercial, tecnológica e organizacional. (HARVEY, 2003, p. 140). 
Esses processos implicaram em uma nova geografia das empresas. A tendência de organização das empresas no sistema flexível passa a ser em forma de redes. Essa empresa-rede "tem a característica de mais ancorar no território do que criar raízes, posto que está sempre posta a migrar para outras paragens que apresentem maiores vantagens" (LENCIONI, 2008). Entretanto, existem elementos que favorecem ou limitam essa mobilidade. A mãode-obra qualificada é um dos elementos centrais na produção contemporânea - como anteriormente apontado, o capital não pode eliminar o trabalho vivo do processo de criação de valores - e as mudanças técnicas e organizacionais do trabalho exigem um novo tipo de trabalhador capaz de, por exemplo, operar e fazer a manutenção do equipamento com que trabalha.

31 O SENAI unidade São Gonçalo estruturou todo o primeiro ciclo de qualificação profissional do Comperj, com os cursos armador de ferro, carpinteiro de formas, eletricista, encanador, pedreiro e pintor predial. Essa atuação proporcionou uma expansão e maior reconhecimento da instituição. Esta funcionava em uma estrutura limitada nas dependências do SESI São Gonçalo até 2009, com um pouco mais de 1000 alunos, oferecendo cursos que nas áreas de "gestão"; "tecnologia da informação" (TI) e "eletricidade, rede e distribuição". Hoje a instituição possui prédio próprio com oficinas de mecânica, de caldeiraria e de solda; e laboratórios de hidráulica, pneumática, cimentação, eletrônica, eletrotécnica e informática.

\section{Considerações finais}

O Leste Metropolitano fluminense vem sofrendo alterações significativas desde o anúncio de implantação do Comperj em 2006. Nesta perspectiva, este trabalho procurou tecer uma análise das políticas de qualificação profissional, destacando os efeitos destas na estruturação das instituições de formação profissional presentes na região. Tanto as instituições privadas quanto as públicas procuram estruturar seus cursos de acordo com as novas demandas do mercado de trabalho.

As políticas de qualificação profissional geralmente definem o desemprego como uma situação conjuntural resultante da falta de formação dos trabalhadores, e partem do pressuposto que a condição social dos indivíduos é resultante da sua formação. Unem em sua argumentação diferentes conceitos e pressupostos analíticos muitas vezes antagônicos, demonstrando uma incoerência teórica que coloca em xeque a validade dessas políticas. Sob nenhuma hipótese, ocorrem reflexões tão importantes que envolvam a complexibilidade do mundo do trabalho e a próprias condições sociais dos trabalhadores.

\section{BIBLIOGRAPHY}

ANTUNES, Ricardo. Os sentidos do trabalho: ensaio sobre a afirmação e negação do trabalho. São Paulo: Boitempo, 2009. 
AS POLÍTICAS DE EMPREGO, TRABALHO E RENDA E AS AÇõES DE QUALIFICAÇÃO. Convênio MTE/ SPPE/CODEFAT - Nº 075/2005 e Primeiro Termo, DIEESE, 2007. Disponível em: http:// www.mte.gov.br/observatorio/sumario_2009_TEXTOV7.pdf. Acesso em: 10 de setembro de 2011. COMPERJ. Potencial de Desenvolvimento Produtivo. Estudos para o Desenvolvimento do Estado do Rio de Janeiro. Elaboração Técnica FGV Projetos, N.1ㅜ 1, Maio 2008.

SIMTEMA FIRJAN- Federação das Indústrias do Estado do Rio de Janeiro. DECISÃO RIO / Investimentos 2008-2010. Disponível em: http://www.firjan.org.br/main.jsp?

lumChannelId=402880811F24243A011F243843420638. Acesso em: 11 de setembro de 2011 .

FERRETTI, Celso João. Modernização Tecnológica, Qualificação Profissional e Sistema de Ensino Público. São Paulo em Perspectiva, 7 (1): 84-91, janeiro/março, 1993.

FONSECA, Marília. Políticas Públicas para a Qualidade da Educação Brasileira: Entre o Utilitarismo Econômico e a Responsabilidade Social. Caderno Cedes, Campinas, vol. 29, n.ำ 78, maio/agosto de 2009, pp. 153-177.

HARVEY, David. Condição pós-moderna: uma pesquisa sobre as origens da mudança cultural. $12^{\mathrm{a}}$ edição. São Paulo: Ed. Loyola, 2003.

LENCIONI, Sandra. Da metrópole como estratégia desenvolvimentista à metrópole como sobrevida do capitalismo. In: PEREIRA, Paulo César Xavier, HIDALGO, Rodrigo. Producción inmobiliaria y reestructuración metropolitana en América Latina. Santiago: PUC-Chile, 2008, p.41-54.

OLIVEIRA, Floriano José Godinho de. Reestruturação econômica, planos de desenvolvimento e mudanças territoriais no Estado do Rio de Janeiro. Revista de Economia Fluminense, v.2 Ano II, p. 6-17, 2007.

------. Investimentos públicos e desenvolvimento local: sentidos estratégicos dos recentes projetos e políticas públicas no Rio de Janeiro. Scripta Nova (Barcelona), v. XII, p. 84, 2008.

PHQ. Plano Nacional de Qualificação (2003-2007). Brasília : MTE, SPPE, 2003. Disponível em: http:// www.trabalho.al.gov.br/configuracao/arquivos/manuais/Pnq_2003_07.pdf. Acesso em 10 de setembro de 2011.

PRESTES, Emília, VÉRAS, Roberto de Oliveira. Educação, Qualificação, Trabalho e Políticas Públicas: campos em disputa. Revista Lusófona de Educação, v. 14, p. 45-59, 2009.

RAMOS, Carlos Alberto. Políticas de geração de emprego e renda: Justificativas teóricas, contexto histórico e experiência brasileira. Texto para Discussão n.ำ 277. Brasília: UNB, 2003. Disponível em: https://www.mpes.gov.br/anexos/centros_apoio/arquivos/11_206217149852009_gera\%C3\%A7\% C3\%A3o\%20de\%20emprego\%20e\%20renda\%20Bras\%C3\%ADlia.pdf. Acesso em: 5 de setembro de 2011.

RAMOS, Tatiana Tramontani. Reestruturação produtiva e precarização das relações de trabalho. Anais do XV Encontro Nacional de Geógrafos, 20 a 26 julho de 2008 / São Paulo - SP.

RIMA - Relatório de Impacto Ambiental. Complexo Petroquímico do Rio de Janeiro.< Disponível em: http://www2.petrobras.com.br/portal/frame.asp?pagina=/Petrobras/portugues/comperj.asp \&area=apetrobras\&lang=pt. Acesso em 11 de setembro de 2011.

SEGNINI, L. R. P. Educação e Trabalho: uma relação tão necessária quanto insuficiente. São Paulo em Perspectiva, v. 14, p. 72-81, 2000.

SOJA, Edward W. Geografias Pós-Modernas: a reafirmação do espaço na teoria social crítica. Rio de Janeiro: Jorge Zahar Editores, 1993. 


\section{ABSTRACTS}

Este trabalho analisa as relações entre as políticas de qualificação profissional e a territorialização de investimentos produtivos por meio do debate sobre a reestruturação produtiva, enfocando os impactos na estruturação das instituições de formação profissional no município de São Gonçalo na década de 2000.

This article intends to analyze the relations between the politics of professional certifications and territorialization of productive investments through the debate on productive restructuration. It focuses on the impacts on the structure of professional education institutes in the city of São Gonçalo in the first decade of the 21st century.

Cet article veut étudier les rapports entre les politiques de qualification professionnelle et la territorialisation des investissements dans la production à la lumière de la restructuration productive. On va souligner les impacts de cette restructuration sur les institutions de la formation professionnelle dans la municipalité de São Gonçalo pendant la décade de 2000.

\section{INDEX}

Mots-clés: travail, territoire, qualification professionelle, restructuration productive, São Gonçalo (RJ)

Keywords: work, territory, professional certifications, productive restructuration

Palavras-chave: trabalho, território, qualificação profissional, reestruturação produtiva

\section{AUTHOR}

\section{TAÍS DE SANTANA FERREIRA}

Estudante do Programa de Pós-Graduação em Geografia (Mestrado) na Universidade Federal do Rio de Janeiro (UFRJ) 